\title{
Ice Dynamics at the Mouth of Ice Stream B, Antarctica
}

\author{
R. A. Bindschadler, ${ }^{1}$ S. N. Stephenson, ${ }^{2}$ D. R. MacAyeal, ${ }^{3}$ \\ AND S. SHABTAIE ${ }^{4}$
}

\begin{abstract}
Field data collected at the mouth of Ice Stream B show that the flow dynamics of this region are distinctly different than either the major portion of the ice stream upstream or the ice shelf downstream. Surface slopes in this region are as low as ice shelf surface slopes, yet with the exception of patches of ice which may be floating, the ice is grounded. Basal shear stress is negligible, the resistance to flow being partitioned between shear at the sides and longitudinal gradients of longitudinal and transverse stress. The surface is generally crevasse-free. Features similar to ice rises are observed upstream of the grounding line. Their origin is uncertain, but they move at velocities comparable to the surrounding ice. The flow is laterally extensive and longitudinally compressive, but there are large local variations of the strain rate from the regional trends. The boundary between the two major tributaries to Ice Stream B, followed with the radar, is characterized by a band of strain rates much smaller than average. Detailed measurements at the downstream B network highlight this local variability of strain rates but confirm that there is a strong correlation between surface topography and strain rates. The strain rates indicate that the undulating topography is locally generated. The lower-elevation ice is thicker and moves faster. A velocity profile across the crevassed northern margin shows that the decrease of velocity toward the edge is nearly linear. A calculation of ice stream discharge at this location agrees closely with two rather rough estimates of balance flux and is considerably larger than a third estimate. The discharge of Ice Stream B does not appear to be significantly out of balance with published estimates of total ice accumulation within the present catchment basin.
\end{abstract}

\section{INTRODUCTION}

The West Antarctic ice sheet is a marine ice sheet grounded on bedrock well below sea level [Drewry, 1983] which may make it prone to large and possibly rapid fluctuations in volume. Mercer [1968] has suggested that the West Antarctic ice sheet disappeared during the Sangamon Interglacial 125,000 years B.P. when global sea level was approximately 5 $\mathrm{m}$ higher than present. Denton and Hughes [1981] have calculated that during the last major glacial period 18,000 years B.P. West Antarctica was $50 \%$ larger in volume than present and that the margin of the ice sheet extended to the edge of the continental shell. Presently, the ice sheet is between these two extremes, but the current rate of volume change is not known. The response behavior of the West Antarctic ice sheet is an essential element of understanding the role of ice sheets in the climate system and is particularly relevant to the current concern about future changes in sea level [Meier, 1985].

There have been many attempts to model the response of the West Antarctic ice sheet [Budd et al., 1984; Denton and Hughes, 1981; Lingle, 1984, 1985; Thomas, 1985; Thomas et al., 1978, 1979; van der Veen, 1985]. All of these models have had to link the dynamics of slow moving ice, suitable for the interior of the ice sheet, with the dynamics of the floating ice shell by specifying the dynamics of the ice streams which connect the interior ice sheet to the ice shelf. However, without a thorough understanding of the physics of basal sliding or the geophysical setting existing underneath the ice streams, the dynamics of ice stream flow in these models has had to rely on

\footnotetext{
${ }^{1}$ NASA Goddard Space Flight Center, Greenbelt, Maryland.

${ }^{2}$ Science Applications Research, Lanham, Maryland.

${ }^{3}$ Department of Geophysical Sciences, University of Chicago, Illinois.

${ }^{4}$ Geophysical and Polar Research Center, University of Wisconsin-Madison.

Copyright 1987 by the American Geophysical Union.

Paper number 6B6117.

0148-0227/87/006B-6117\$05.00
}

rather ad hoc assumptions. Therefore the results of such models must be viewed with a very cautious eye.

Presented in this paper are data collected in the region of the mouth of Ice Stream B, West Antarctica, during three field seasons (1983-1984 through 1985-1986). These data provide an excellent opportunity for understanding the ice flow in the mouth of an active ice stream as well as the interaction of ice stream and ice shell because Crary Ice Rise, the largest ice rise of the Ross Ice Shelf lies directly in the path of Ice Stream B as it enters the ice shelf.

\section{Physical Characteristics of the Mouth of ICE STream B}

At the outset of the field program, no reliable map of this area was available. Airborne radar data gathered by the University of Wisconsin have been particularly useful in providing a good map of surface elevation, including the boundaries of the major ice features [Shabtaie and Bentley, 1987]. Most of the surface-based work in this region consisted of the establishment of single and double lines of surface stakes and threelegged strain rosettes [Thomas et al., 1984] for measuring both surface velocity and strain rates. Figure 1 is taken from Bindschadler et al. [1987] and shows the location and names given to many of the rosettes established by the NASA/University of Chicago program.

The measurements presented here are confined to the area that extends for $160 \mathrm{~km}$ from rosette $\mathrm{G} 2$ (near $84^{\circ} \mathrm{S}, 150^{\circ} \mathrm{W}$ ) to just upstream of Crary Ice Rise (see Figure 1). Figure 2, taken from the larger map of Shabtaie and Bentley [1987] shows this area in more detail. The surface of the region is relatively flat and crevasse-free with the exception of the ice stream margins. The boundary of the ice stream is well defined on the north by a band of intense crevassing (called the "Snake") some $10 \mathrm{~km}$ wide. The southern edge of Ice Stream B is more diffuse, consisting of separate narrow bands of crevasses. The radar measurements allow the crevasse units to be traced even after the confluence of Ice Streams A and B. Thus the divergence of Ice Stream B can be measured in this region. From a width of approximately $70 \mathrm{~km}$ at $\mathrm{G} 2$, the ice stream widens to $130 \mathrm{~km}$ 


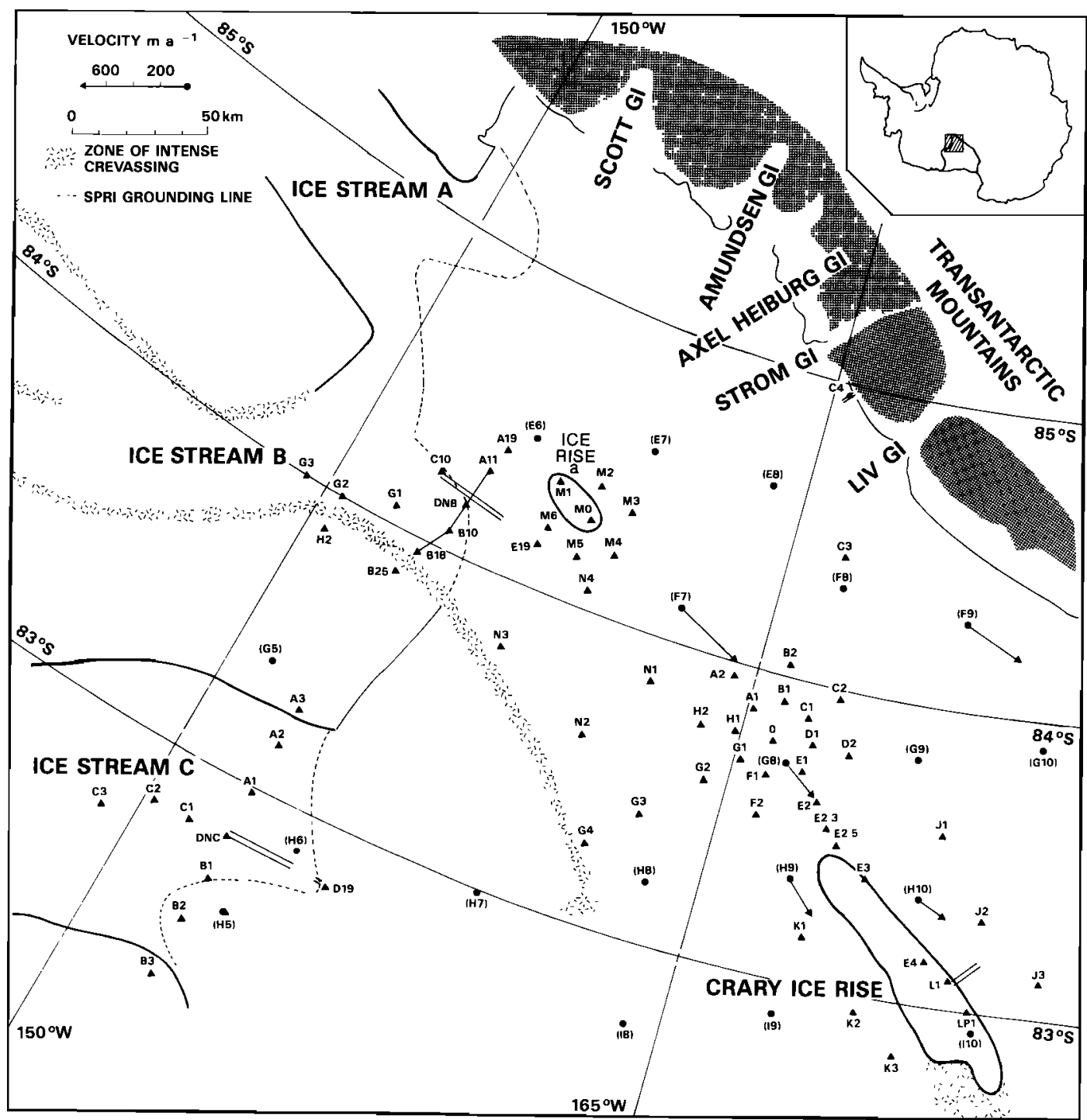

Fig. 1. Map taken from Bindschadler et al. [1987] showing the area of field studies including Crary Ice Rise and the mouths of Ice Streams A, B, and C. Solid triangles are strain rosettes established during this project. Single or double lines indicate single or double stake line strann networks. Solid circles are RIGGS stations identified by parenthesized station names. Avalable velocities of RIGGS stations are included [Thomas et al., 1984]. Boundaries of ice streams are from Drewery [1983]. The boundary of Crary Ice Rise is from our analysis.

at $\mathrm{A} 1$, a longitudinal distance of $150 \mathrm{~km}$. Using a mean velocity of $500 \mathrm{~m} \mathrm{yr}^{-1}$, this corresponds to a lateral strain rate of $2.0 \times 10^{-3} \mathrm{yr}^{-1}$.

Another feature of this ice stream is the presence of elongated undulations. The direction of elongation is not exactly parallel to the direction of motion but deviates from it by about $20^{\circ}$. Bindschadler et al. [1987, Figure 8] showed the characteristic scale of these undulations near DNB; the nearlongitudinal wavelength of the undulations varies between 10 and $20 \mathrm{~km}$ while the transverse wavelength varies between 5 and $8 \mathrm{~km}$. Their height is typically $10 \mathrm{~m}$ peak to trough.

The measured regional slope in this area was zero over a $30-\mathrm{km}$ line whose azimuth $\left(278^{\circ}\right.$ true) was within $11^{\circ}$ of the azimuth of ice stream motion (269 $9^{\circ}$ true). Using Magnavox MX1502 satellite geoceivers, an elevation difference of $51 \mathrm{~m}$ was measured for the $130-\mathrm{km}$ distance between DNB and station G2 near Crary Ice Rise, an average gradient of 0.4 $\times 10^{-3}$. This value is much smaller than surface slopes of other ice streams [Drewry, 1983] including Ice Stream B
[Whillans, 1984]. This low surface slope is more typical of slopes of ice shelves [Thomas, 1979] and suggests a very low value for the basal shear stress.

The method of using geoceiver-derived elevations to map surface topography is relatively new to ice sheet studies. Its advantage is that it does not depend on line-of-sight links with a previous grid. The accuracy of the method is still being established. Whillans et al. [this issue] uses translocation to decrease relative errors in both position and elevation. The data presented here used position and elevations obtained from point positioning using the MX1502 geoceiver broadcast ephemeris but no translocation. When three optical level lines were surveyed between six geoceiver-occupied stations, the misclosure was about $3 \mathrm{~m}$ in each case. From repeated multiple-pass measurements of elevation using MX1502 geoceivers and spaced 1 year apart, the differences between elevations had a mean of $3.6 \mathrm{~m}$. This is somewhat better consistency than the repeatability of $10 \mathrm{~m}$ found on Rutford Ice Stream by C. S. M. Doake (personal communication, 1986). 


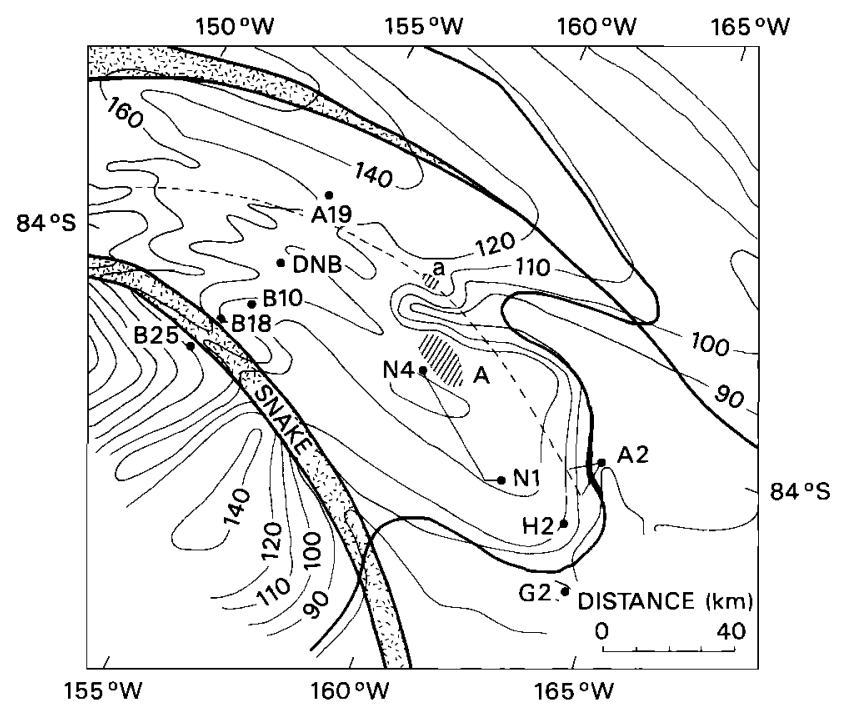

Fig. 2. Map of the mouth of Ice Stream B taken from Shabtaie and Bentley [1987]. Surface contours (in meters) are from alrborne radar profiling. Stippled areas indicate the boundaries of Ice Stream B defined by radar backscatter. Single thick solid line indicates the grounding line defined from radar features and hydrostatic equilibrium considerations. Heaviest line indicates where grounding line position was confirmed by surface observations of strand cracks and optical leveling. Thin dashed line marks the boundary between the two major tributaries of Ice Stream B. Shaded areas are radar features " $A$ " and " $a$ " with ice rise-like radar signatures. Thin lines between $\mathrm{N} 1$ and $\mathrm{N} 4$ as well as A2 show location of levelung lines. Labeled dots are survey statıons.

Combining optically leveled segments with elevations determined by geoceiver, Figure 3 gives a sample of a longitudinal profile for the lower Ice Stream B. Figure 3 includes spot measurements of ice thickness using a University of Wisconsin radar designed for surface work. Measurements were made at hall-kilometer spacings along three level lines: N4 to N1, and two lines each $10 \mathrm{~km}$ long starting at $\mathrm{A} 2$ in the directions of $\mathrm{N} 1$ and $\mathrm{H} 2$ (see Figure 2). These measurements show that the ice thickness profile exhibits spatial variations that are similar in magnitude to the surface undulations. The ice thins gradually from $828 \mathrm{~m}$ at DNB to $650 \mathrm{~m}$ at station G2 near Crary Ice Rise; a thickness gradient of $1.3 \times 10^{-3}$. Using an average velocity of $500 \mathrm{~m} \mathrm{yr}^{-1}$ over this $130-\mathrm{km}^{-1}$ distance, the average vertical strain rate is $-0.9 \times 10^{-3} \mathrm{yr}^{-1}$.

The combination of surface elevation and ice thickness is a powerful technique for determining grounded ice from floating Ice even when the elevations are not referenced to mean sea level [Shabtaie and Bentley, 1987; Bindschadler et al., 1987]. Using this technique, along with surface observations of strand cracks [Swithinbank, 1958], we have modified slightly the position of the grounding line as plotted by Shabtaie and Bentley [1987]. Level data along the line from A2 to N1 (see Figure 2 for station positions) across the grounding line show that the grounding line is marked by a change in elevation of only $4 \mathrm{~m}$ over a horizontal distance of $1.5 \mathrm{~km}$.

Although the surface gradient is similar to those observed at other grounding lines, the actual change in elevation is an order of magnitude smaller. It is possible that this smaller change may be more typical for active ice streams. While airborne radar is not usually able to detect such a small change in elevation, the grounding line in the central part of Ice Stream B does seem to follow roughly the steeper slope indicated by the $90-$ and $100-\mathrm{m}$ contours (see Figure 2).
Ice rumples were found in the region between the Ice Stream B grounding line and Crary Ice Rise. Bindschadler et al. [1987] first reported these ice rumples, and Shabtaie and Bentley [1987] have evidence of other rumples in this region from radar measurements of bottom crevasses. Doake et al. [this issue] report that the rumple-type features seen on enhanced Landsat imagery of the Rutford Ice Stream are indeed grounded. It is quite likely that a similar region containing patches of grounded ice exists downstream of the Ice Stream B grounding line, and due to the proximity of Crary Ice Rise this region may be quite extensive.

The two features indicated by "A" and " $a$ " in Figure 2 were identified as ice rises by Shabtaie and Bentley [1986] based on their radar signatures, which are free of backscatter from buried surface crevassing in their center but surrounded by increased backscatter at the margin. Nevertheless, these features cannot be ice rises because as Shabtaie and Bentley's [1986, Figure 1] map showed, they are surrounded by grounded ice rather than ice shelf. Also, as will be discussed later, the center of the feature marked "a" is flowing at $460 \mathrm{~m} \mathrm{yr}^{-1}$ with no evidence of shear between it and the adjacent ice stream. Dynamically, the ice contained within these features appears identical to the surrounding ice. These features may be relic ice rises, formed when the grounding line was less advanced but incorporated into the ice stream during a period of grounding-line advance. Alternatively, C. R. Bentley (personal communication, 1986) and I. M. Whillans (personal communication, 1986) have suggested that these features may be islands of undisturbed ice that have been torn from the inland ice upstream during the activation phase of Ice Stream B and

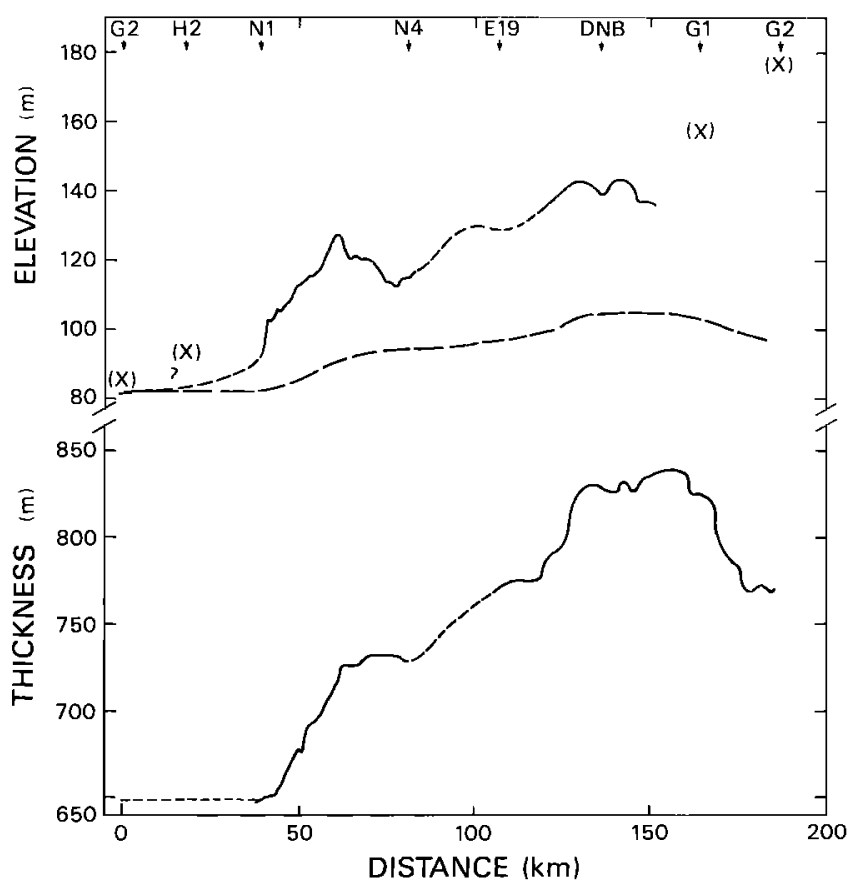

Fig 3 Longitudınal profiles of thickness and surface topography at the mouth of Ice Stream B (see Figure 2 for locations). The solid lines are where the surface was optically leveled and the ice thickness was sounded with surface and arborne radar. The dashed line is where the surface elevation was interpolated between geocelver elevations. Long dashed line is theoretical surface elevation if the measured ice thickness were in hydrostatic equilibrium with the sea. Note that the vertical exaggerations of surface and ice thickness scales are different 


\section{DOWNSTREAM B \\ (LONGITUDINAL LINE)}

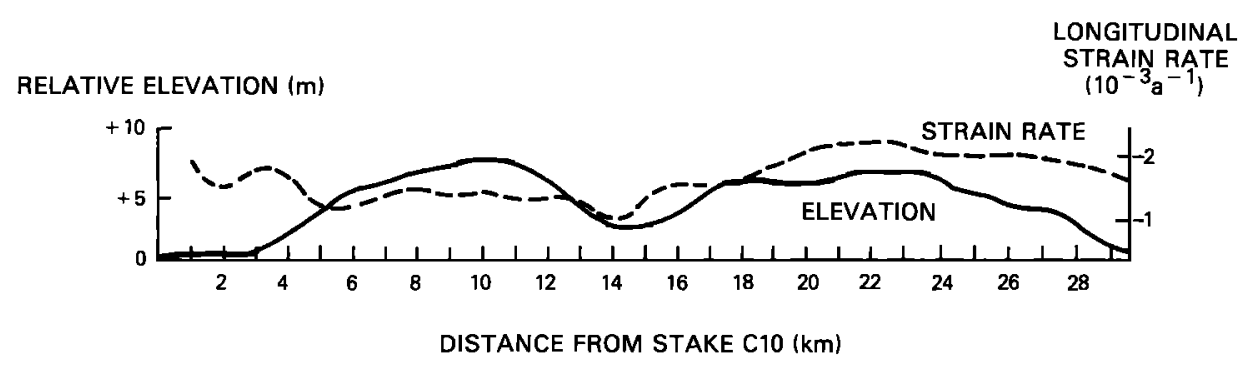

Fig. 4. Optically leveled surface profile (solıd line) and longitudinal strain rate (dashed line) along a longitudinal double stake line starting at $\mathrm{C} 10$ on the DNB grid (see Figure 1). Flow is from left to right.

subsequently carried along the ice stream. The tearing process would account for the increased backscatter around the margin. D. G. Shultz (personal communication, 1986), has collected densely spaced airborne radar data in four blocks along the ice stream and may be able to trace a succession of these types of features.

\section{DYNAMICS IN THE VICINITY OF DNB NeTwORK}

Many detailed measurements have been made of surface velocity, strain rate, topography, and ice thickness in the region covered by the DNB network. These data give an excellent opportunity to learn about the nature of the ice flow in the mouth of Ice Stream B before attempting to look at the entire region. As Figure 1 shows, the densely spaced stake network at DNB consists of a double line running longitudinally and a single transverse line kinked at station B10.

Figure 4 shows the variation of surface elevation and strain rate along the longitudinal line. There is both a general compression of about $1.6 \times 10^{-3} \mathrm{yr}^{-1}$ over the $30-\mathrm{km}$ distance and a smaller-scale variation of the strain rate amounting to about half this magnitude. In places there appears to be a correlation between the two profiles, especially on the downstream half where the region of maximum compression occurs

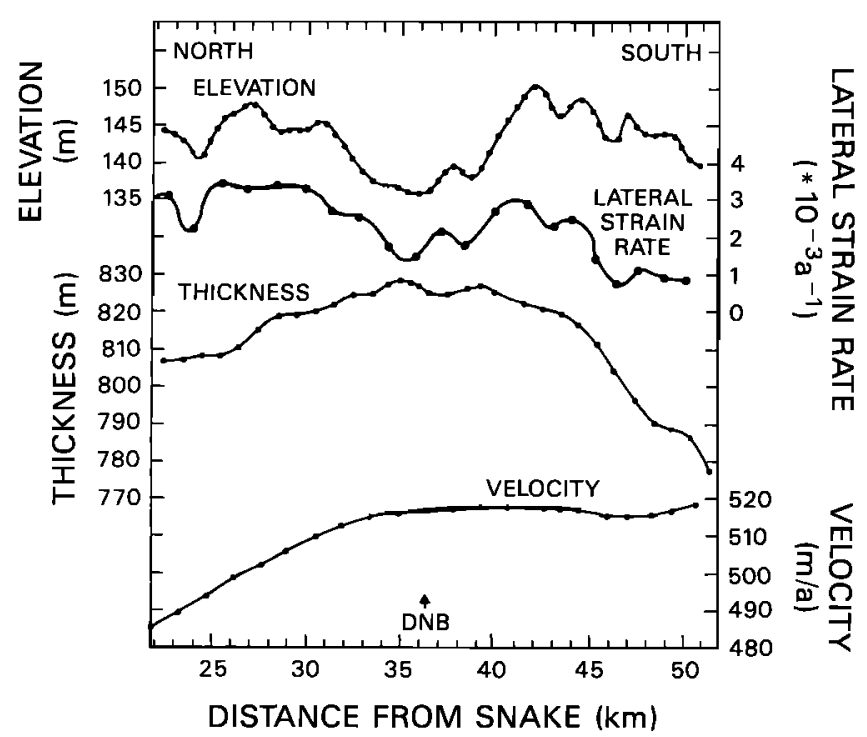

Fig. 5. Transverse profiles of surface elevation, lateral strain rate, ice thickness, and longitudinal velocity along a single transverse stake line at DNB (B10 to Al1). Solid circles show location of measurements. at the region of highest surface. Such a correlation was also found on Rutford Ice Stream [Stephenson and Doake, 1982]. This correlation, however, breaks down on the upstream half of the profile. It is perhaps noteworthy that in our case the stake line is not exactly oriented along the flow direction; this could explain why we cannot confirm the correlation reported on Rutford Ice Stream.

The combination of surface topography and surface strain rate for the $31-\mathrm{km}$ transverse line is shown in Figure 5. The average lateral extension is $2 \times 10^{-3} \mathrm{yr}^{-1}$, equal to the average lateral extension over the $160-\mathrm{km}$ distance from station G2 to the grounding line as Ice Stream B coalesces with Ice Stream $A$ and enters Ross Ice Shelf. In contrast to the longitudinal case there is a very strong correlation between the variation of transverse strain rate and surface topography. The sense of the correlation is that the surface highs are experiencing relatively more lateral tension and the lows are being laterally compressed. Because high spots are thinning while low spots are filling, there is an overall smoothing of the topography occurring. The surface roughness persists downstream, but individual undulations disappear to be replaced by new ones. Thus there must be an active process that is generating this undulated surface.

The rate of decay of these undulations can be examined quantitatively. If the perturbation of lateral strain rate from the mean is $e$ and the height perturbation is $h$, then the rate of thickness change at the perturbation will be

$$
\frac{d h}{d t}=-e * H
$$

where $H$ is the ice thickness. From Figure 5 it is possible to relate $h$ and $e$ by the linear relation

$$
e=h * 2.5 \times 10^{-4}\left(\mathrm{~m}^{-1} \mathrm{yr}^{-1}\right)
$$

Substituting (1) into (2) and integrating over time yields an expression for the decay of the perturbations:

$$
h=h_{0} * \exp \left(-2.5 \times 10^{-4} * H * t\right)
$$

where $h_{0}$ is the original perturbation height. Equation (3) has an decay time scale of 5 years for an ice thickness of $800 \mathrm{~m}$. If the ice is moving at $500 \mathrm{~m} \mathrm{yr}^{-1}$, this corresponds to a horizontal distance of $2.5 \mathrm{~km}$, somewhat shorter but of the same order as the longitudinal extent of these undulations. The longitudinal compression measured on the summit of one of the undulations shown in Figure 4 is further evidence that the formation of these undulations is an active process. At present, we cannot determine the precise nature of the process that 


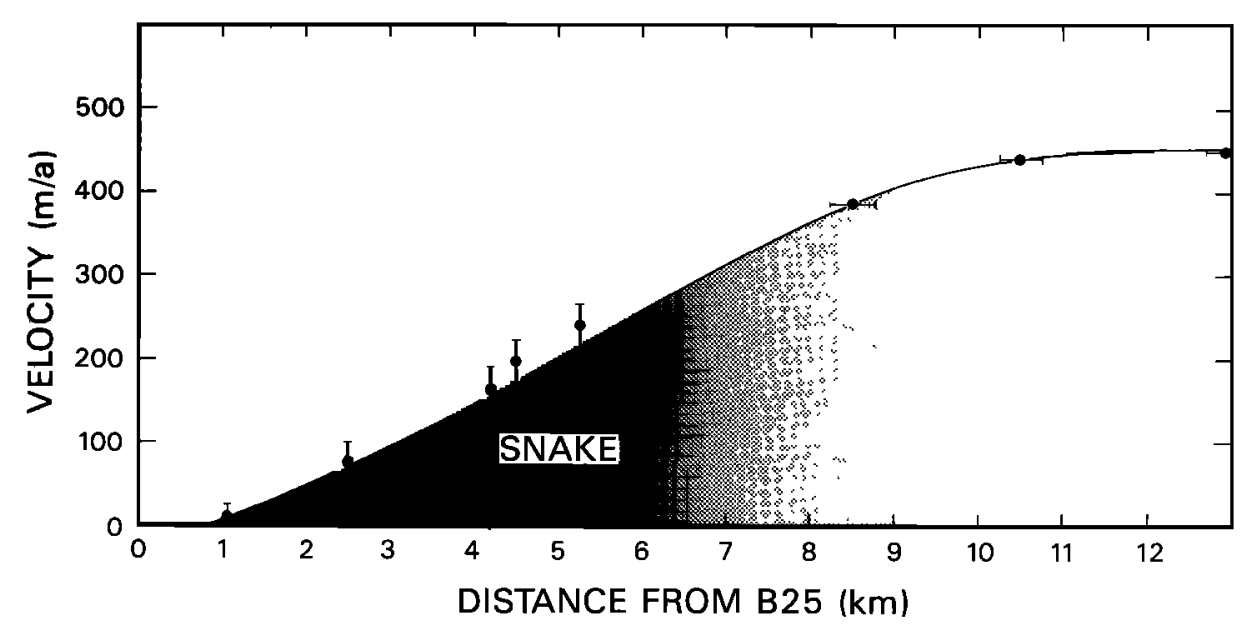

Fig. 6. Velocities at the edge of Ice Stream B. Triangulated serac velocities are shown by solid circles with vertical error bars. Velocities from geoceiver positioning and survey transects are shown by solid circles with horizontal error bars.

creates these undulations. It is likely that it is an expression of variations in the basal shear stress, but these variations could have many origins. It could be a direct result of motion over an undulating bed; it could be a result of variations in thickness of an active, deforming till at the base [Blankenship et al., this issue] or it could be related to the movement of subglacial water at the bed or through the till [Alley et al., this issue; Bindschadler, 1983].

Figure 5 also includes profiles of the longitudinal velocity and ice thickness. Both the velocity and ice thickness profiles are considerably smoother than the profiles of either strain rate or surface topography. The thicker ice occurs at the lowest portion of the surface. There is no obvious correlation of velocity with either the elevation or strain rate profiles.

Velocity data were collected at additional points along this transverse profile: at A19, from B10 to B18 (south of the Snake), and into the Snake from B25 which is a station north of the Snake (see Figure 1). The velocity at A19 was $490 \pm 10$ $\mathrm{m} \mathrm{yr}^{-1}$, lower than the $517 \pm 10 \mathrm{~m} \mathrm{yr}^{-1}$ at DNB. A19 is also somewhat higher in elevation than DNB. At B25, triangulation of a number of seracs within the Snake (a method used by Swithinbank [1963]) was carried out over a 20-day period

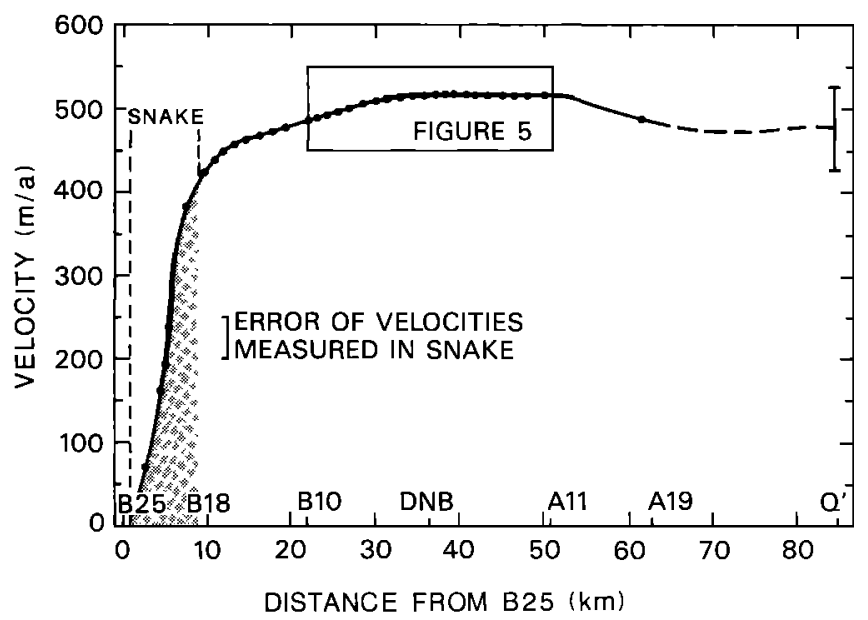

Fig. 7. Profile of velocity across Ice Stream B. Solid circles show location of measurements. Profile is extended to a point $Q^{\prime}$ where expected range of velocity was estimated using the strain rate measured at A19. from a $600-\mathrm{m}$ baseline. The resultant velocities have rather large uncertainties of $\pm 20 \mathrm{~m} \mathrm{yr}^{-1}$, but they give a reasonable fit to a linear velocity profile (see Figure 6). There is no evidence of slip-fault-type motion. A similar profile obtained by measuring the sides of stake quadrilaterals at the side boundary of Crary Ice Rise showed a slight curve, but any nonlinearity in the profile across the Snake could easily be hidden in the errors of the individual velocity points. The three velocities in Figure 6 farthest from the Snake were determined from the survey transect and the DNB velocity. The value of velocity at B18 (11 km from B25) agreed with an independent measurement of its velocity determined from repeated geoceiver positions to within $4 \mathrm{~m} \mathrm{yr}^{-1}$.

Figure 7 combines the two velocity profiles and the A19 velocity to give a velocity profile across all but the southernmost part of Ice Stream B. The profile was completed by extrapolation. Using an average velocity of $481 \mathrm{~m} \mathrm{yr}^{-1}$ (assuming no decrease of velocity with depth), an ice stream width of $86 \mathrm{~km}$ and an average ice thickness, corrected for the low-density firn, of $771 \mathrm{~m}$, the calculated discharge is $32 \pm 2$ $\mathrm{km}^{3} \mathrm{yr}^{-1}$. This is slightly larger than the published estimates of balance flux: $29 \mathrm{~km}^{3} \mathrm{yr}^{-1}$ [Hughes, 1973], $18 \mathrm{~km}^{3} \mathrm{yr}^{-1}$ [Rose, 1978], and $30 \mathrm{~km}^{3} \mathrm{yr}^{-1}$ [Lingle and Brown, 1987]. However, given the large amount of uncertainty in the accumulation rate and catchment area boundaries necessary to calculate balance flux, we do not feel that the apparent negative net mass balance is significant.

\section{Dynamics of ICE Stream B From DNB TO THE Grounding LiNe}

Figure 8 presents the measured surface velocities. Figure 9 presents the measured principal strain rates at the surface. Clearly, the velocity field is much more uniform than the highly variable strain rate field. Figures 4 and 5 showed that there can be large differences between the local and regional strain rates. On the broad scale (from DNB to G2 near Crary Ice Rise) the average lateral extension is $2.0 \times 10^{-3} \mathrm{yr}^{-1}$ and the average vertical strain rate is $0.9 \times 10^{-3} \mathrm{yr}^{-1}$, as stated in an earlier section. Thus, from incompressibility the average longitudinal compression is $1.1 \times 10^{-3} \mathrm{yr}^{-1}$. Figure 9 shows that there are many measurements of local strain rate which deviate significantly from these regional values. These local strain rate measurements can be considered to represent the 


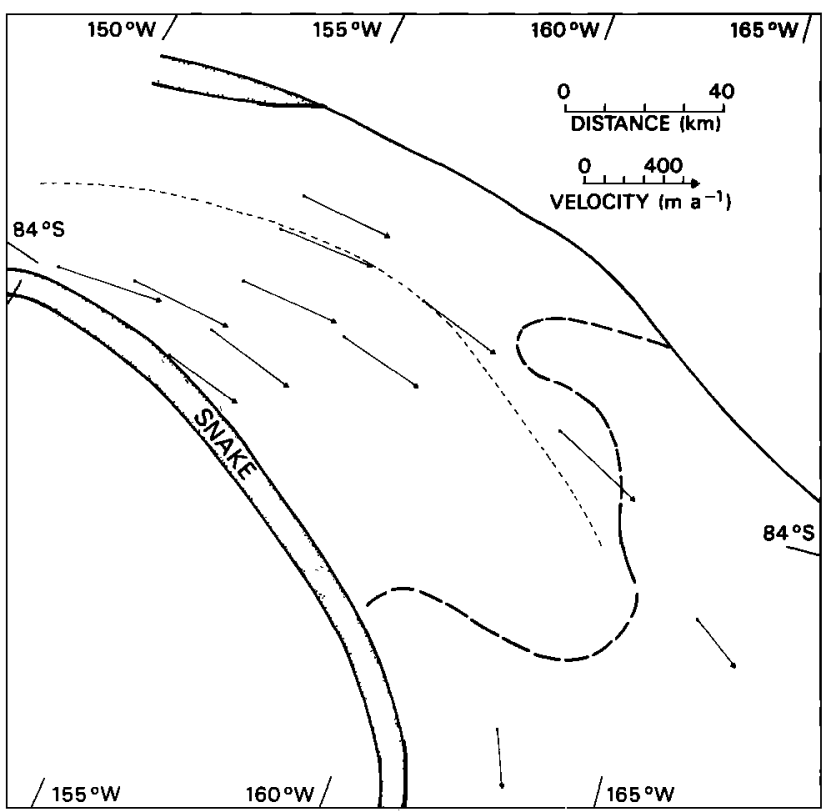

Fig. 8. Velocities in the mouth of Ice Stream B determined by geoceiver positioning. Mapped features are taken from Figure 2.

strain field within a circular area $1.5 \mathrm{~km}$ in radius; the length of a rosette leg [see Thomas et al., 1984]. At stations directly adjacent to the Snake there is very strong shear taking place; $10 \mathrm{~km}$ into the ice stream from the Snake, each measurement shows longitudinal compression and lateral extension which is consistent with the overall trend. Nearer the features " $A$ " and " $a$ " (see Figure 2) the situation is more complex, indicating greater spatial variability in the strain rate field. There is no obvious expression of deformation connected with the presence of these two "ice rises." The ice at the farthest extent of Ice Stream B is already feeling the presence of Crary Ice Rise, as evidenced by the increasing compression as the ice rise is approached.

\section{Force ANalysis of the Grounding LiNe Region}

One goal of our data analysis is to evaluate the relative importance of various resistive forces, such as basal shear, side shear, and longitudinal stress gradients, to ice stream flow through examination of the surface strain rates that we have measured. First, we derive an exact expression for the basal shear stress $\tau_{b}$ and then simplify it using appropriate assumptions to render it useful for our data analysis. Our treatment of the governing stress balance equations closely parallels that of Whillans [1987] Alley et al. [this issue], Budd [1970], and Nye [1969]. A minor difference between our derivation that follows and this previous work is that we adopt a bedreferenced coordinate systern which permits $\tau_{b}$ to be specified in a more natural manner.

The reference frame adopted is shown in Figure 10; the $x$ axis is locally tangent to the base and points in the downstream direction, the $y$ axis is horizontal and perpendicular to the flow, and the $z$ axis is normal to the bed and points upward. In this coordinate system the base is at $z_{b}$, the surface at $z_{s}$, and $\left(z_{B}-z_{b}\right)=H \sec \beta$, where $H$ is the local ice thickness and $\beta$ is the local base slope.

The stress equilibrium equations in this reference frame are written

$$
\begin{gathered}
\frac{\partial \tau_{x x}}{\partial x}+\frac{\partial \tau_{x y}}{\partial y}+\frac{\partial \tau_{x z}}{\partial z}=\rho g \sin \beta \\
\frac{\partial \tau_{x y}}{\partial x}+\frac{\partial \tau_{y y}}{\partial y}+\frac{\partial \tau_{y z}}{\partial z}=0 \\
\frac{\partial \tau_{x z}}{\partial x}+\frac{\partial \tau_{y z}}{\partial y}+\frac{\partial \tau_{z z}}{\partial z}=\rho g \cos \beta
\end{gathered}
$$

where $\rho$ is ice density, $g$ is gravitational acceleration, and $\tau_{i j}$ is the stress tensor. The boundary conditions at the bed (and $x=0$ ) are a mixture of dynamic and kinematic conditions. The kinematic condition is that the basal ice must flow parallel to the bed; thus we ignore basal melting in this analysis. The dynamic conditions at the base, expressed in their exact form, are

$$
\begin{array}{rr}
-\tau_{x z}+\tau_{x y} \frac{\partial z_{b}}{\partial y}=-\tau_{b} & \text { at } z=z_{b} \\
-\tau_{y z}+\tau_{x y} \frac{\partial z_{b}}{\partial x}=0 & \text { at } z=z_{b}
\end{array}
$$

Because the $x$ axis is tangent to the bed, $\partial z_{b} / d x$ is zero at $x=0$. This simplifies (8). The dynamic conditions at the free surface, also expressed in their exact form, are

$$
\begin{array}{ll}
\tau_{x z}-\tau_{x x} \frac{\partial z_{s}}{\partial x}-\tau_{x y} \frac{\partial \dot{z}_{s}}{\partial y}=0 & \text { at } z=z_{s} \\
\tau_{y z}-\tau_{y y} \frac{\partial z_{s}}{\partial y}-\tau_{x y} \frac{\partial z_{s}}{\partial x}=0 & \text { at } z=z_{s} \\
\tau_{z z}-\tau_{x y} \frac{\partial z_{s}}{\partial x}-\tau_{y z} \frac{\partial z_{s}}{\partial y}=0 & \text { at } z=z_{s}
\end{array}
$$

Because the ice motion near the grounding line is primarily due to sliding and the ice is nearly supported by buoyant forces, the strain rates will be depth-independent. Thus we proceed in this development by detiving a formula for $\tau_{b}$ expressed in terms of depth-integrated deviatoric stresses, which are, in turn, related to the strain rates through the flow law. The deviatoric stresses $\tau_{i j}{ }^{\prime}$ are defined as

$$
\tau_{i j}^{\prime}=\tau_{i j}-\delta_{i j} P
$$

where

$$
P=\frac{1}{3}\left(\tau_{x x}+\tau_{y y}+\tau_{z z}\right)
$$

and $\delta_{i j}$ is the Kroniecker delta. Integrating (4) over the ice thickness (from $z_{b}$ to $z_{s}$ ) and using Leibnitz' rule, equation (12), and the boundary conditions expressed in (7) and (9),

$$
\begin{aligned}
\partial\left[\int_{z_{b}}^{z_{x}} \tau_{x x^{\prime}} d z\right] / \partial x & -\partial\left[\int_{z_{b}}^{z_{s}} P d z\right] / \partial x \\
& +\partial\left[\int_{z_{b}}^{z_{s}} \tau_{x y} d z\right] / \partial y-\tau_{b}=\rho g H \tan \beta
\end{aligned}
$$

Next, we integrate (6) from $z$ to $z_{s}$ and use Leibnitz' rule again and the boundary condition expressed in (11) to obtain

$$
\begin{aligned}
P(z)=\tau_{z z}{ }^{\prime}+\rho g & \cos \beta\left(z_{s}-z\right) \\
& -\partial\left[\int_{z}^{z_{s}} \tau_{x z} d z\right] / \partial x-\partial\left[\int_{z}^{z_{s}} \tau_{y z} d z\right] / \partial y
\end{aligned}
$$




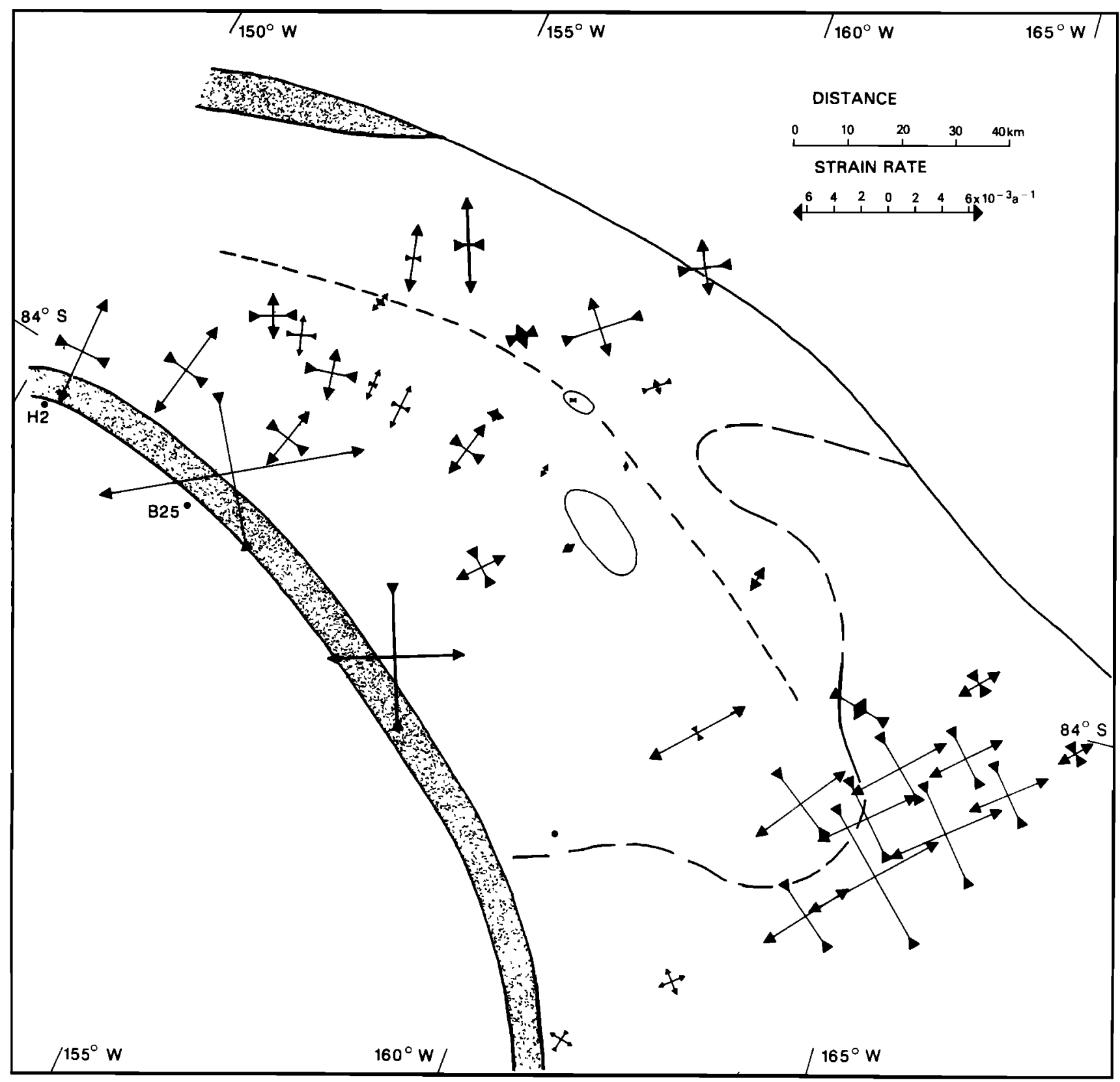

Fig. 9. Surface strain rates in the mouth of Ice Stream B. Deformation is represented by strain figures showing the magnitude and orientation of the principal strain rates. Mapped features are taken from Figure 2.

Applying the incompressibility condition,

$$
\tau_{z z}^{\prime}=-\tau_{x x}^{\prime}-\tau_{y y}^{\prime}
$$

Equation (15) can be rewritten

$$
\begin{aligned}
P(z)=-\tau_{x x}{ }^{\prime}- & \tau_{y y}{ }^{\prime}+\rho g \cos \beta\left(z_{s}-z\right) \\
& -\partial\left[\int_{z}^{z_{s}} \tau_{x z} d z\right] / \partial x-\partial\left[\int_{z}^{z_{s}} \tau_{y z} d z\right] / \partial y
\end{aligned}
$$

Using (17) to substitute for $P(z)$ in (14), we obtain the exact relationship

$$
\begin{aligned}
\partial\left[\int_{z_{b}}^{z_{s}}\left(2 \tau_{x x}{ }^{\prime}+\tau_{y y}\right) d z\right] / \partial x-\rho g H \partial[H \sec \beta] / \partial x \\
+\partial\left[\int_{z_{b}}^{z_{s}} \tau_{x y} d z\right] / \partial y-\rho g H \tan \beta-\tau_{b}
\end{aligned}
$$

$$
\begin{aligned}
& +\partial\left[\int_{z_{b}}^{z_{s}} \partial\left(\int_{z}^{z_{s}} \tau_{x z} d z\right) / \partial x d z\right] \partial x \\
& +\partial\left[\int_{z_{b}}^{z_{s}} \partial\left(\int_{z}^{z_{s}} \tau_{y z} d z\right) / \partial y d z\right] / \partial x=0
\end{aligned}
$$

The last two terms on the left-hand side of (18) are referred to as "arching stress" terms by Whillans [1987] and are negligible wherever the square of the aspect ratio (thickness to horizontal scale) is small [Whillans, 1987; Alley and Whillans, 1984]. This condition is satisfied in our application, hence we simplify (18) by disregarding these two terms. A further simplification can be realized by the approximation,

$$
\partial[H \sec \beta] / \partial x=\tan (\alpha-\beta) \approx \tan \alpha-\tan \beta
$$

where $\alpha$ is the surface slope. Substituting (19) into (18) pro- 


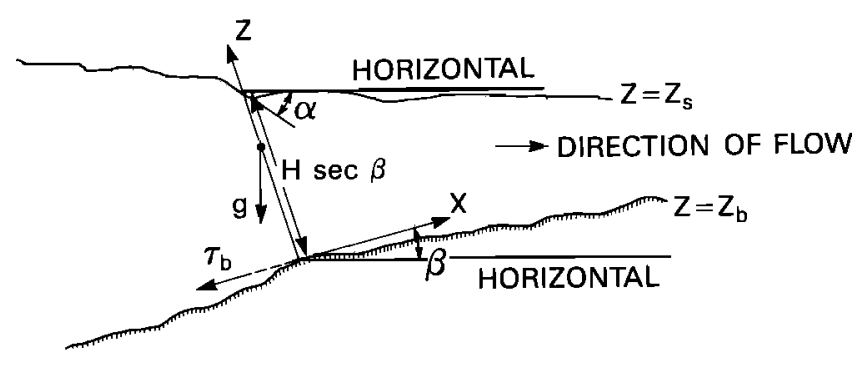

Fig. 10. Coordinate system used in force analysis.

duces the simplified relation

$\tau_{b}=\partial\left[\int_{z_{b}}^{z_{s}}\left(2 \tau_{x x}{ }^{\prime}+\tau_{y y}{ }^{\prime}\right) d z\right] / \partial x+\partial\left[\int_{z_{b}}^{z_{s}} \tau_{x y} d z\right] / \rho g H \tan \alpha$

which expresses the basal shear stress in terms of measurable depth-integrated stress gradients and the surface slope. This equation is similar to that used in other treatments of ice dynamics which account for longitudinal deviatoric stresses [Alley and Whillans, 1984; van der Veen, 1984].

To apply (20) to field data, it is first necessary to derive the depth-integrated stresses from the measurements of surface strain rate. We use the nonlinear flow law proposed by Glen [1955] and generalized by $N y e$ [1957] which relates the deviatoric stresses to the strain rates:

$$
\dot{\varepsilon}_{\imath \jmath}=A \tau^{\prime n-1} \tau_{\nu,}^{\prime}
$$

where $A$ is a temperature-dependent coefficient, $n$ is the power law exponent (assumed equal to three in this paper), and $2 \tau^{\prime 2}$ is the second invariant of the deviatoric stress tensor. Equation (21) can be rewritten in the form

$$
\tau_{i j}{ }^{\prime}=\left(A \dot{\varepsilon}^{2}\right)^{-1 / 3} \dot{\varepsilon}_{i j}
$$

where $2 \dot{\varepsilon}^{2}$ is the second invariant of the strain rate tensor. Both $A$ and $\tau_{i j}{ }^{\prime}$ vary with depth, but the $\dot{\varepsilon}_{i j}$ do not. The depth dependence of $A$ can be calculated from a temperature versus depth profile [see Paterson, 1981]. This permits the calculation of the depth-averaged deviatoric stress components, $\bar{\tau}_{i j}$, from (22). Using data from DNB of ice thickness $(828 \mathrm{~m})$, accumulation rate ( $0.10 \mathrm{~m}$ of ice per year), surface temperature $\left(-26.1^{\circ} \mathrm{C}\right)$, and a temperate base, an equilibrium temperature profile was calculated. The depth-averaged value of $A$ was $0.0127 \mathrm{bar}^{-3} \mathrm{yr}^{-1}$ corresponding to an effective temperature of $-12.9^{\circ} \mathrm{C}$. Using this value and (22), the depth-averaged stresses were calculated along the longitudinal stake network at DNB and are shown in Figures 11 and 12. While there is considerable variation for each stress component, the overall pattern is one of decreasing longitudinal compression and increasing transverse tension with distance downstream. This same value of $A$ was used, along with an average shear strain rate of $5.56 \times 10^{-2} \mathrm{yr}^{-1}$ across the Snake, to calculate an average shear stress across the Snake of 1.6 bars. This should be considered as an upper bound. The presence of additional stresses, warmer temperatures, or enhanced fabric development [Hughes, 1977] would all tend to lower this calculated shear stress across the Snake.

These data, along with the measurements of geometry, permit the calculation of $\tau_{b}$ for this region. Table 1 presents the relative contribution of each term along with the formula used to evaluate each term. The longitudinal gradients of the longitudinal and transverse stresses are taken by fitting straight lines to the data in Figures 11 and 12. In each case, only the average gradient is taken over the full longitudinal distance. For the side shear a value of 1.6 bars within the Snake was calculated above. On the other side of the ice stream, however, there is little apparent shear between Ice Streams A and B. Thus we assume zero shear at this edge. The stream width is $86 \mathrm{~km}$. Finally, the last term in (20) is zero because the surface slope is zero. The sum of these terms gives a value of $0.003 \pm 0.007$ bar for the base shear stress. This amount is not significantly different from zero given the uncertainty in our calculations. The major error in this calculation comes from values of the stress gradients, but it is worth noting that the longitudinal gradients tend to compensate each other: when one gradient is larger than the mean, the gradient of the other stress tends to be smaller than the corresponding mean along that same segment.

Over the larger area, from DNB to the grounding line, a similar force analysis can be completed (see Table 1). This time, however, there is a surface slope of $0.4 \times 10^{-3}$, and the average thickness is $735 \mathrm{~m}$ for an average driving stress of

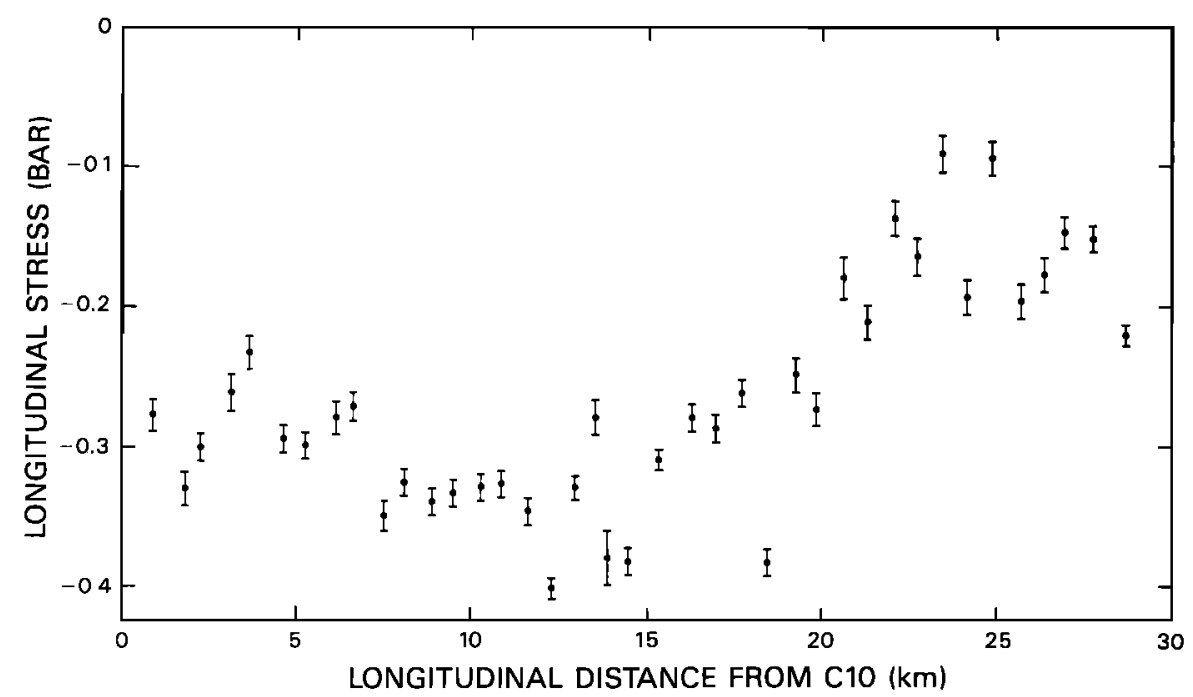

Fig. 11. Profile of depth-averaged longitudinal deviatoric stress along the longitudinal double stake line between C10 and E10 on the DNB grid (see Figure 1). 


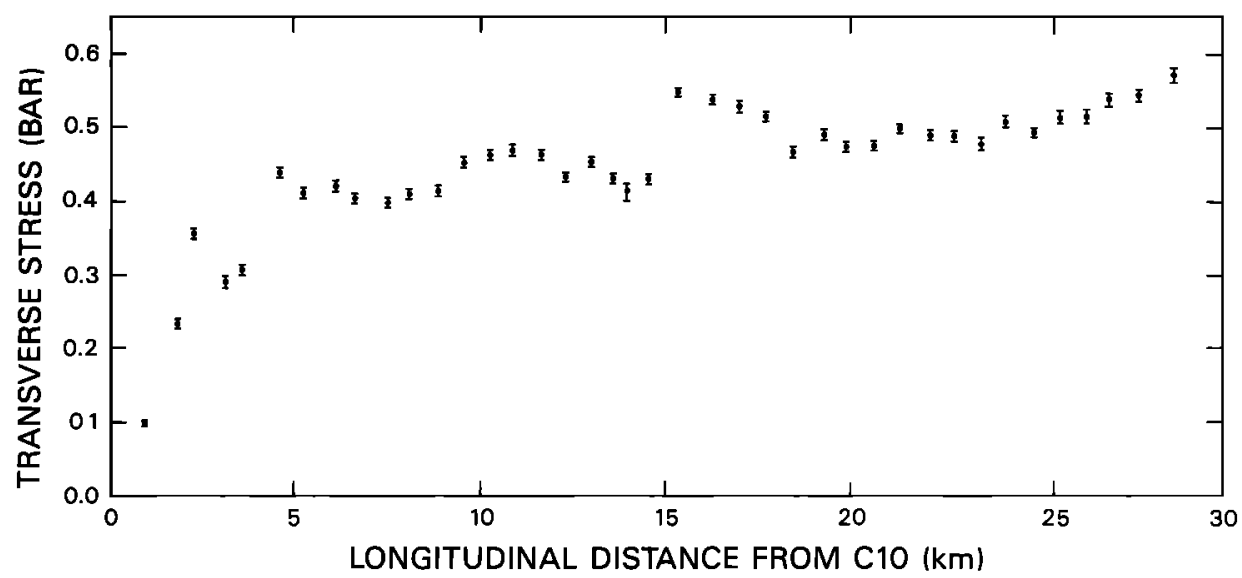

Fig. 12. Profile of transverse deviatoric stress along the longitudinal double stake line between $\mathrm{C} 10$ and E10 on the DNB grid (see Figure 1).

0.026 bar. The longitudinal stress gradient terms will be small because they are being averaged over a distance 50 times longer than the local calculation at DNB. Thus longitudinal stress gradients are neglected. The side shear term is calculated assuming that the shear stress is zero at the boundary between the two Ice Stream B tributaries and 1.6 bars across the Snake. The average width of the northern Ice Stream B tributary is $55 \mathrm{~km}$. Therefore this side shear term equals -0.021 bar for a base shear stress of $0.004 \pm 0.005$ bar. Again, this is a negligible amount considering the uncertainty (primarily due to uncertainty in value of side shear).

\section{Discussion}

From our analysis we have demonstrated that the dynamic situation of this region at the mouth of Ice Stream B is distinctly different from either the greater portion of the ice stream upstream or the Ross Ice Shelf downstream. The driving stress is small throughout this region. Side shear and longitudinal stress gradients are of near-equal importance in balancing the driving stress (see Table 1). The basal shear stress is negligible as a resistive force, but small variations in basal shear are responsible for the undulated surface topography (see Figure 5). Thus the ice in this region is being pushed by the ice stream upflow into the Crary Ice Rise downstream and dragged along the sides; all on a near-frictionless bed.

The proximity of either Crary Ice Rise or the grounding line does not affect the regional strain rate field over the majority of the ice stream mouth. Instead, there is a large spatial variability to the strain rate field. The surface elevations within this region are just a few tens of meters above the theoretical elevation for ice of corresponding thickness which is floating. Thus the normal force of this ice on the bed is quite small. It is possible that flotation does occur in small areas upstream of the grounding line just as ice rumples occur on the ice shelf, but this has not been observed along $60 \mathrm{~km}$ of optical level lines (Figure 3). Wherever this local flotation occurs, the ice will still thin, as would any ice shelf, even in the absence of a surface slope. At these locations the basal shear stress would

TABLE 1. Calculation of Base Shear Stress from Equation (20)

\begin{tabular}{|c|c|c|c|}
\hline Term & $\begin{array}{l}\text { Evaluation } \\
\text { Formula }\end{array}$ & $\begin{array}{c}\text { Local } \\
\text { DNB Network }\end{array}$ & $\begin{array}{l}\text { Regional } \\
\text { DNB to H2 }\end{array}$ \\
\hline $\begin{array}{l}H \\
\partial H / \partial x \\
\bar{\tau}\end{array}$ & $\Delta H / \Delta x$ & $\begin{array}{l}828 \pm 5 \mathrm{~m} \\
-1.5 \pm 0.017 \mathrm{~m} / \mathrm{km}\end{array}$ & $735 \pm 10 \mathrm{~m}$ \\
\hline $\begin{array}{l}l_{x x}^{x} \\
\partial \bar{\tau}_{x x}^{\prime} / \partial x \\
\bar{\tau}_{y y}{ }^{\prime}\end{array}$ & $\Delta \bar{\tau}_{x x}^{\prime} / \Delta x$ & $\begin{aligned} 0.75 & \pm 0.33 \mathrm{kPa} / \mathrm{km} \\
45 & \pm 2 \mathrm{kPa}\end{aligned}$ & 0 \\
\hline$\partial \bar{t}_{y y}^{\prime} / \partial x$ & $\Delta \bar{\tau}_{y y}^{\prime} / \Delta x$ & $0.67 \pm 0.33 \mathrm{kPa} / \mathrm{km}$ & 0 \\
\hline & & $\begin{array}{c}160 \pm 30 \mathrm{kPa} \\
86 \pm 2 \mathrm{~km}\end{array}$ & $\begin{array}{c}160 \pm 30 \mathrm{kPa} \\
55 \pm 2 \mathrm{~km}\end{array}$ \\
\hline$\alpha$ & & 0 & $-0.39 \pm 0.03 \mathrm{~m} / \mathrm{km}$ \\
\hline$\partial\left[\int_{z_{b}}^{z_{s}} 2 \tau_{x x}^{\prime} d z\right] / \partial x$ & $\begin{array}{l}2 H\left(\Delta \bar{\tau}_{x x}^{\prime} / \Delta x\right) \\
\quad+2 \bar{\tau}_{x x}^{\prime}(\Delta H / \Delta x)\end{array}$ & $\begin{array}{l}1.31 \pm 0.56 \mathrm{kPa} \\
0.07 \pm 0.01 \mathrm{kPa}\end{array}$ & $\begin{array}{l}\mathbf{0} \\
\mathbf{0}\end{array}$ \\
\hline$\partial\left[\int_{z_{b}}^{z_{s}} \tau_{y y}^{\prime} d z\right] / \partial x$ & $\begin{array}{l}H\left(\Delta \bar{\tau}_{y y}^{\prime} / \Delta x\right) \\
\quad+\bar{\tau}_{y y}^{\prime}(\Delta H / \Delta x)\end{array}$ & $\begin{array}{c}0.56 \pm 0.28 \mathrm{kPa} \\
-0.07 \pm 0.004 \mathrm{kPa}\end{array}$ & $\begin{array}{l}0 \\
0\end{array}$ \\
\hline$\partial\left[\int_{z_{\mathrm{b}}}^{z_{\mathrm{s}}} 2 \tau_{x y} d z\right] / \partial y$ & $\begin{array}{l}H \cdot \tau_{x y /} / W \\
\quad+\tau_{x y}(\Delta H / \Delta y)\end{array}$ & $\begin{array}{c}-1.53 \pm 0.29 \mathrm{kPa} \\
0 ?\end{array}$ & $\begin{array}{c}-2.14 \pm 0.41 \mathrm{kPa} \\
0 ?\end{array}$ \\
\hline $\begin{array}{l}\rho g H \tan \alpha \\
\tau_{b}\end{array}$ & $\begin{array}{l}\rho g H \tan \alpha \\
\text { equation (20) }\end{array}$ & $\begin{array}{c}0 \\
0.28 \pm 0.69 \mathrm{kPa} \\
(0.003 \pm 0.007 \mathrm{bar})\end{array}$ & $\begin{array}{r}2.58 \pm 0.20 \mathrm{kPa} \\
0.44 \pm 0.46 \mathrm{kPa} \\
(0.004 \pm 0.005 \mathrm{bar})\end{array}$ \\
\hline
\end{tabular}


be zero, and if a driving stress exists, it would be balanced by longitudinal stress gradients and side shear as at DNB. If this flotation condition were attained for ice above the flotation thickness, for instance, due to pressurized subglacial water [Bindschadler, 1983; Alley et al., this issue; Lingle, 1986] the creep thinning rates would exceed those calculated by Weertman [1957] for an ice column in hydrostatic equilibrium because of the excess ice thickness above sea level. This region, then, can perhaps best be described as a hybrid between an ice stream and an ice shelf; possessing the grounded characteristic of an ice stream but the low surface slope and low basal friction characteristic of an ice shelf.

Acknowledgments. Field programs only succeed when many people whose names never appear as authors contribute a great deal of time and energy. Our thanks go out to the field assistants of both the NASA/University of Chicago and University of Wisconsin field program who helped collect the data on which this paper is based: James Foster, Dean Lindstrom, Richard Otto, Erıc Roberts, John Scofield, Matthew Sturm, David Thompson, and Jay Zwally. Excellent logistical support was provided by National Science Foundation, Polar Operations. A special thanks to Robert Thomas, who first conceived of the study and who was instrumental in preparing the initial proposal. Thomas, along with Charles Bentley and Ian Whillans provided thorough reviews of an earlier draft of this paper which helped improve the presentation of our results. NASA provided the salary for one of us (R.A.B.). The major financial support was provided by the National Science Foundation through grants DPP-8207320, DPP-8405287, DPP-8514543, and DPP-8414402.

\section{REFERENCES}

Alley, R. B., and I. M. Whillans, Response of East Antarctic ice sheet to sea-level rise, J. Geophys. Res., 89, 6487-6493, 1984.

Alley, R. B., D. D. Blankenship, S. T. Rooney, and C. R. Bentley, Till beneath ice stream B, 3, Till deformation. Evidence and implications, J. Geophys. Res., this issue.

Bindschadler, R. A., The importance of subglacial water in separation and sliding at the glacier bed, J. Glaciol., 29, 3-19, 1983.

Bindschadler, R. A., D. R. MacAyeal, and S. N. Stephenson, Ice stream-1ce shelf interaction in West Antarctica, in Dynamics of the West Antarctic Ice Sheet, edited by C. J. van der Veen and J. Oerlemans, pp. 161-180, D. Reidel, Hingham, Mass., 1987.

Blankenship, D. D., C. R. Bentley, S. T. Rooney, and R. B. Alley, Till beneath ice stream B, 1, Properties derived from seismic travel times, J. Geophys. Res., this issue.

Budd, W. F., The longitudinal stress and strain rate gradients in ice masses, J. Glacıol., 9(55), 19-27, 1970.

Budd, W. F., D. Jenssen, and I. N. Smith, A three-dimensional timedependent model of the West Antarctic ice sheet, Ann. Glaciol., S, 29-36, 1984.

Denton, G. H., and T. J. Hughes (Eds.), The Last Great Ice Sheets, John Wiley, New York, 1981.

Doake, C. S. N., R. M. Frolich, D. R. Mantripp, A. M. Smith, and D. G. Vaughan, Glaciological studies on Rutford Ice Stream, Antarctica, J. Geophys. Res., this issue.

Drewry, D., Antarctica: Glaciological and Geophysical Folio, Scott Polar Research Institute, University of Cambridge, Cambridge, England, 1983.

Glen, J., The creep of polycyrstalline ice, Proc. R. Soc. London, Ser. A, 238(1175), 519-538, 1955 .

Hughes, T. J., Is the West Antarctic ice sheet disintegrating?, J. Geophys. Res., 78, 7884-7910, 1973.

Hughes, T. J., West Antarctic ice streams, Rev. Geophys., 15, 1-46, 1977.

Lingle, C. S., A numerical model of interactions between a polar ice stream and the ocean: Application to Ice Stream E, West Antarctica, J. Geophys. Res., 89, 3523-3549, 1984.

Lingle, C. S., A model of a polar ice stream and future sea-level rise due to possible drastic retreat of the West Antarctic ice sheet, in Glaciers, Ice Sheets, and Sea-Level: Effects of a $\mathrm{CO}_{2}$-Induced Clımatic Change, edited by M. F. Meier, National Academy Press, Washington, D. C., 1985.

Lingle, C. S., The West Antarctic 1ce sheet may necessarily be characterized by discharge through fast-flowing ice streams, paper presented at the Chapman Conference on Fast Glacier Flows: Ice Streams, Surging, and Tidewater Glaciers, AGU, Vancouver, B. C. May 5-8, 1986.

Lingle, C. S., and T. J. Brown, Subglacial aquifer bed model and water pressure-dependent basal sliding relationship for the West Antarctic ice streams, in Dynamics of the West Antarctic Ice Sheet, edited by C. J. van der Veen and J. Oerlemans, D. Reidel, Hingham, Mass., in press, 1987.

Meier, M. F. (Ed.), Glaciers, Ice Sheets, and Sea-Level: Effects of a $\mathrm{CO}_{2}$-Induced Climatic Change, National Academy Press, Washington, D. C., 1985.

Mercer, J. H., Antarctic ice and Sangamon sea level, IAHS Publ., 79, 217-225, 1968.

Nye, J. F., The distribution of stress and velocity in glaciers and ice sheets, Proc. R. Soc. London, Ser. A, 239(1216), 113-133, 1957.

Nye, J. F., The effect of longitudinal stress on the shear stress at the base of an ice sheet, J. Glaciol., 8(53), 207-213, 1969.

Paterson, W. S. B., The Physics of Glaciers, 2nd ed., Pergamon, New York, 1981.

Rose, K. E., Radio echo sounding studies of Marie Byrd Land, Antarctica, Ph.D. thesis, Univ. of Cambridge, Cambridge, England, 1978.

Shabtaie, S., and C. R. Bentley, Ice streams and grounding zones of West Antarctica and the Ross Ice Shelf (abstract), Ann. Glaciol., 8 , $199,1986$.

Shabtaie, S., and C. R. Bentley, West Antarctic ice streams draining into Ross Ice Shelf: Configuration and mass balance, J. Geophys. Res., 92, 1311-1336, 1987.

Stephenson, S. N., and C. S. M. Doake, Dynamic behavior of Rutford Ice Stream, Ann. Glaciol, 3, 295-299, 1982.

Swithinbank, C. W. M., Morphology of the ice shelves of western Dronning Maud Land, in Norwegian-British-Swedish Antarctic Expedition, Scientific Results, vol. 5, Glaciology, p. 18, 1958.

Swithinbank, C. W. M., Ice movement of valley glaciers flowing into the Ross Ice Shelf, Antarctica, Science, 41, 523-524, 1963.

Thomas, R. H., The dynamics of marine ice sheets, J. Glaciol., 24(90), 167-178, 1979.

Thomas, R. H., Response of the polar ice sheets to climatic warming, in Glaciers, Ice Sheets, and Sea-Level Effects of a $\mathrm{CO}_{2}$-Induced Climatic Change, edited by M. F. Meier, pp. 301-316, National Academy Press, Washington, D. C., 1985.

Thomas, R. H., and C. R. Bentley, A model for Holocene retreat of the West Antarctic ice sheet, Quat. Res., 10, 150-170, 1978.

Thomas, R. H., T. J. O. Sanderson, and K. E. Rose, Effect of climatic warming on the West Antarctic ice sheet, Nature, 227, 355-358, 1979.

Thomas, R. H., D. R. MacAyeal, D. H. Eilers, and D. R. Gaylord Glaciological studies on the Ross Ice Shelf, Antarctica, 1973-1978, in The Ross Ice Shelf. Glaciology and Geophysics, Antarct. Res. Ser. vol. 42, edited by C. R. Bentley and D. E. Hayes, pp. 21-53, AGU, Washington, D. C., 1984.

van der Veen, C. J., Response of a marine ice sheet to changes at the grounding line, Quat. Res., 24, 257-267, 1985.

van der Veen, C. J., Numerical modelling of ice shelves and ice tongues, Ann. Geophys., 4, 45-54, 1986

Weertman, J., Deformation of floating ice shelves, J. Glaciol., 3(21), 39-42, 1957.

Whillans, I. M., Ice stream dynamics, Antarct. J. U.S., $I 9(5), 51-53$ 1984.

Whillans, I. M., Force balance of ice sheets, in Dynamics of the West Antarctic Ice Sheet, edited by C. J. van der Veen and J. Oerlemans, pp. 249-285, D. Reidel, Hingham, Mass., 1987.

Whillans, I. M., J. Bolzan, and S. Shabtaie, Velocity of Ice Streams B and $\mathrm{C}, J$. Geophys. Res., this issue.

R. A. Bindschadler, Code 671, NASA Goddard Space Flight Center, Greenbelt, MD 20771.

D. R. MacAyeal, Department of Geophysical Sciences, 573 S. Ellis Ave., University of Chicago, Chicago, IL 60637

S. Shabtaie, Geophysical and Polar Research Center, University of Wisconsin-Madison, Madison, WI 53706.

S. N. Stephenson, Science Applications Research, 4400 Forbes Blvd, Lanham, MD 20706.

(Received June 11, 1986; revised November 20, 1986; accepted January 27, 1987.) 